\title{
Analysis of queue change of visitors and performace system in the Department of Population and Civil Regristation of Semarang City
}

\author{
Sugito*, Alan Prahutama, Dwi Ispriyanti, and Mustafid
}

Statistics Department, Faculty of Science and Mathematics, Diponegoro University, Semarang, Indonesia

\begin{abstract}
The Population and Civil Registry Office in Semarang city is one of the public service units. In the public service sector, visitor / customer satisfaction is very important. It can be identified by the length of the queue, the longer visitors queue this results in visitor dissatisfaction with the service. Queue analysis is one of the methods in statistics to determine the distribution of queuing systems that occur within a system. In this study, a queuing analysis as divided into two periods. The first period lasts from 2-13 March 2015, while the second period lasts November $16^{\text {th }}$ to December 20 2019 . The variables used are the number of visitors and the service time at each counter in intervals of 30 minutes. The results obtained are changes in the distribution and queuing model that is at counter $5 / 6$ and counter 10 . The queuing model obtained at the second perideo for the number of visitors and the time of service with a General distribution. The average number of visitors who come in 30 minute intervals in the second period is more than the first period, this indicates an increase in visitors. The opportunity for service units is still small, the waiting time in the queue is getting smaller. This shows that the performance of the queuing system at the Semarang Population and Civil Registry Office is getting better.
\end{abstract}

Keywords. Queue system, the number of arrivlas, the time of served, General Distribution, Poisson Distribution

\section{Introduction}

Queuing is a common thing and often happens in everyday life. Most people consciously or unconsciously, have experienced a queue situation or often referred to as a waiting situation. The queue process is a process related to the arrival of a customer at a service facility, then waits in line or queue if it has not received service and finally leaves the

\footnotetext{
*Corresponding author: sugitostat@gmail.com
} 
service facility after receiving service [1]. The queue occurs because many people need services at the same time and the number of individuals coming in exceeds the number of service facilities available. This queue situation is usually found in public service places. One example is the visitors of queue that occurs at the Office of Population and Civil Registration (Dispendukcapil) of Semarang City.

The Department of Population and Civil Registration (Dispendukcapil) has the task of assistance in the field of population and civil registration. Civil registration services in the form of services relating to births, deaths, marriages, divorce and other civil registration issues. The large number of Indonesian citizens can affect the number of births, deaths, marriages, and divorces. Usually marriages affect the number of births can also affect divorce. These matters must be reported by the community to Dispendukcapil so that the local government has complete information about the community.

The number of visitors who come every working day causes the Semarang City Dispendukcapil to not be able to serve the community to the fullest because of the limited service time with visitors who come to exceed the agency's resource capacity. One of the incidents that usually happens at Dispendukcapil is a situation where visitors queue up in the service counter, especially at counter 4 (counters counter legalized). By taking a queue notation that is the number of arrivals per unit time $(\lambda)$ and the number served per unit time $(\mu)$ is expected to provide the best service that is providing fast service, so that visitors are not left to wait long to get their turn. Visitors come to the service with random, irregular, and cannot be served immediately so they have to wait for quite a long time [2].

In this study changes in the queuing model distribution will be compared. Distribution changes are made based on the time of research data collection. The first period was taken from March $2^{\text {nd }} 2015$ to March $13^{\text {th }}$ 2015, while the second period was taken from December $16^{\text {th }} 2019$ to November $20^{\text {th }} 2019$. This paper will compare the distribution and queuing model of the number of arrivals and service times. Also analyzed are changes in the performance of the queuing system between the first and second periods.

\section{Literature Review}

\subsection{The Queuing System}

According to Kakiay (2004) [3], a queue is a waiting line of a number of customers who require service from one or more service facilities. A queuing process is a process associated with the arrival of a number of customers at a service facility, then waits in a queue line if it cannot be served, and finally leaves the service facility after being served. While the queuing system is a set consisting of customers, servants, and a rule that regulates service to customers. There are several important factors that are closely related to the queuing system. The factors that influence the queue and service lines are the distribution of arrival, the distribution of time services, the facility of services, service discipline, the measure of queue, source of calling.

According to Taha (1996) [4], Kendall's notation is used to detail the characteristics of a queue. Appropriate notation for summarizing the main characteristics of parallel queues has been universally standardized in the following format:

$$
(\mathrm{a} / \mathrm{b} / \mathrm{c}):(\mathrm{d} / \mathrm{e} / \mathrm{f})
$$

$\mathrm{a}$ : arrival distribution; $\mathrm{b}$ : the distribution of time services; $\mathrm{c}$ : the facility of services (for $\mathrm{c}=1,2,3, \ldots \infty)$; $\mathrm{d}$ : service discipline (FIFO, LIFO, SIRO, and priority of services); e : The size of the system in the queue or the maximum number allowed in the system (finite 
or infinite); $\mathrm{f}$ : Number of customers who want to enter the system as a source (finite or infinite);

Steady state conditions are met if the value of the level of usefulness $(\rho)<1$ means the average rate of arrival of visitors to the death counter is smaller than the average rate of service. This can also be interpreted that a condition where the number of visitors who come are still able to be served effectively and vice versa if the arrival rate of visitors is too much so that the server is not able to serve all of them there will be a buildup of visitors queue.For example $\lambda$ is the average number of customers who come to the service per unit of time and $\mu$ is the average number of customers that have been served per unit of time, then [5].

$$
\rho=\frac{\lambda}{\mu}
$$

\subsection{Poisson Process}

According to Gross and Harris (1998) [6], the process of number of arrivals is considered $\{\mathrm{N}(\mathrm{t}), \mathrm{t} \geq 0\}$, where $\mathrm{N}$ is denoted the number of arrivals that occur until time $\mathrm{t}$, with $\mathrm{N}(0)$ $=0$, which follows the three assumptions as follows:

1. The probability of one arrival occurring between time $\mathrm{t}$ and $t+\Delta t$ is equal to $\lambda \Delta \mathrm{t}+\mathrm{o}(\Delta \mathrm{t})$. It can be written that $\mathrm{Pn}=$ arrivals occur between $\mathrm{t}$ and $\mathrm{t}+\Delta \mathrm{t}\}=$ $\lambda \Delta \mathrm{t}+\mathrm{o}(\Delta \mathrm{t})$, where $\lambda$ is a constant that is independent of $\mathrm{N}(\mathrm{t}), \Delta \mathrm{t}$ is an added time element, and $\mathrm{o}(\Delta \mathrm{t})$ is denoted as the number of arrivals that can be ignored when compared with $\Delta \mathrm{t}$, with $\Delta \mathrm{t} \rightarrow 0$, yaitu $: \lim _{\Delta \mathrm{t} \rightarrow 0} \frac{\mathrm{o}(\Delta \mathrm{t})}{\Delta \mathrm{t}}=0$

2. Pn (t) \{more than one arrival between $\mathrm{t}$ and $\mathrm{t}+\Delta \mathrm{t}$ \} is very small or can be said to be ignored $=\mathrm{o}(\Delta \mathrm{t})$

3. The number of arrivals at successive intervals is fixed / independent, which means that the process has free additions.

\subsection{The testing of Fit Distribution}

According Daniel (1989) [7], there are tho method that used to fit test distribution of observatioan such as Kolmogorov-Smirnov and Chi Quadrat testing. The procedure of Kolmogorov-Smirnov testing as follow as:

Hypothesis of testing

$\mathrm{H}_{0}$ : The distribution of observation is equivalent with Poisson distribution

$\mathrm{H}_{1}$ : The distribution of observation is Not equivalent with Poisson distribution with significant level $\alpha$, and the test of statistics is

$$
\mathrm{D}=\sup \left|\mathrm{S}(\mathrm{n})-\mathrm{F}_{0}(\mathrm{n})\right|
$$

Criteria of testing is $\mathrm{H}_{0}$ rejected for $D>\mathrm{D}_{\text {table }}\left(\mathrm{D}^{*} \alpha / 2, \mathrm{n}\right)$ or the value of significant less than significant level where $D_{\text {table }}\left(D^{*} \alpha / 2, n\right)$ is Kolmogorov-Smirnov's table. The procedure of Chi Quadrat testing as:

Hypothesis of testing

$\mathrm{H}_{0}$ : The distribution of observation is equivalent with Poisson distribution 
$\mathrm{H}_{1}$ : The distribution of observation is Not equivalent with Poisson distribution with significant level $\alpha$, and the test of statistics is:

$$
\chi^{2}=\sum_{i=1}^{n} \frac{\left(O_{i}-E_{i}\right)^{2}}{E_{i}}
$$

where $O_{i}$ is observation value $\mathrm{i}$-th; and $E_{i}$ the expected value of observation i-th, for $E_{i}=\frac{n_{i .} n_{. i}}{n}$

Criteria of testing is $\mathrm{H}_{0}$ rejected for $\chi^{2} \geq \chi_{a, v}^{2}$ dengan $\mathrm{v}=\mathrm{r}-1-\mathrm{g}, \mathrm{g}$ is the number of coloumn; $r$ is the number of row.

\section{$2.4(M / G / 1):(G D / \infty / \infty)$ queue model}

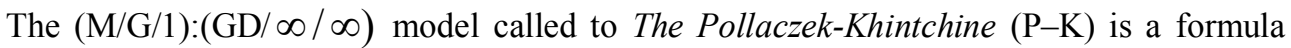
that will be obtained in a single service situation that fulfills the following three assumptions [8]:

1. Poisson arrival with an average arrival $\lambda$.

2. Distribution of general or general service time with average service expectations is

$$
E[t]=\frac{1}{\mu} \text { and variance } \operatorname{var}[\mathrm{t}] \text {. }
$$

3. Steady state with $\rho=\lambda \mathrm{E}\{\mathrm{t}\}<1$ or $\rho=\frac{\lambda}{\mu}<1$.

In the P-K formula, a system performance measurement is obtained for $(\mathrm{M} / \mathrm{G} / 1)$ : $(\mathrm{GD} / \infty / \infty)$ model as follow as:

1. Estimated number of customers in the system:

$$
\mathrm{L}_{\mathrm{s}}=\lambda \mathrm{E}\{\mathrm{t}\}+\frac{\lambda^{2}\left(E^{2}[t]+\operatorname{var}\{t\}\right)}{2(1-\lambda \mathrm{E}\{\mathrm{t}\})}
$$

2. The estimated number of customers in the queue: $\mathrm{L}_{\mathrm{q}}=\mathrm{L}_{\mathrm{s}}-\lambda \mathrm{E}\{\mathrm{t}\}$

3. Estimated time in the system: $\mathrm{W}_{\mathrm{s}}=\frac{L_{s}}{\lambda}$

4. The estimated waiting time in the queue: $\mathrm{W}_{\mathrm{q}}=\frac{L_{q}}{\lambda}$

\section{$2.5(\mathrm{M} / \mathrm{M} / \mathrm{c}):(\mathrm{GD} / \infty / \infty)$ queue model}

In the queuing model the customer arrives with an average arrival rate is $\lambda$ and maximum $\mathrm{c}$ customers who can be served together. By example $r=\lambda / \mu$ and $\rho=r / c=\lambda / c \mu$, probability values for 0 customers can be written [9]:

$$
\mathrm{P}_{0}=\left\{\sum_{\mathrm{n}=0}^{\mathrm{c}-1} \frac{(c \rho)^{\mathrm{n}}}{\mathrm{n} !}+\frac{(\mathrm{c} \rho)^{\mathrm{c}}}{\mathrm{c} !(1-\rho)}\right\}^{-1}
$$


System performance measurement for $(\mathrm{M} / \mathrm{M} / \mathrm{c}):(\mathrm{GD} / \infty / \infty)$ model as follow as:

1. Average waiting in queue:

$$
\mathrm{L}_{\mathrm{q}}=\left(\frac{r^{c} \rho}{c !(1-\rho)^{2}}\right) P_{\mathrm{o}}
$$

2. Average number of customers waiting in the system:

$$
\mathrm{L}_{\mathrm{s}}=\left(\frac{r^{c} \rho}{c !(1-\rho)^{2}}\right) P_{\mathrm{o}}+\mathrm{r}
$$

3. Average time customers wait in a queue:

$$
\mathrm{W}_{\mathrm{q}}=\frac{\mathrm{L}_{\mathrm{q}}}{\lambda}=\left(\frac{r^{c}}{c !(c \mu)(1-\rho)^{2}}\right) P_{0}
$$

4. Average time customers wait in the system:

$$
\mathrm{W}_{\mathrm{s}}=\frac{\mathrm{L}_{\mathrm{s}}}{\lambda}=W_{q}+\frac{1}{\mu}=\frac{1}{\mu}+\left(\frac{r^{c}}{c !(c \mu)(1-\rho)^{2}}\right) P_{0}
$$

\section{$2.6(G / G / c):(G D / \infty / \infty)$ queue model}

The system performance measures in this General model follow the performance measures in the $\mathrm{M} / \mathrm{M} / \mathrm{c}$ model, except for the calculation of the estimated number of customers in the queue (Lq) as follows [10]:

$$
L q=L q_{M / M / c} \frac{\mu^{2}+v(t)+v\left(t^{\prime}\right) \lambda^{2}}{2}
$$

with $v(t)$ is a variant of service time; $v\left(t^{\prime}\right)$ is a variant of interarrival times.

\section{Methodology Of Research}

The data used in this study are primary data, that is data taken from observations and records of visitors at the Semarang City Dispendukcapil office. The study period was divided into two periods, the first period was 2-13 March 2015, while the second period was 16 December to 20 November 2020. The variables used in this study were data on the number of arrivals and service times of visitors at the Semarang City Dispendukcapil office. The steps in conducting research and data analysis are as follows:

1. Conducting visitor research at the Semarang City Population and Civil Registry Office, in this case data must be obtained regarding the arrival time used to get the number of arrivals per unit time $(\lambda)$, the service time used to get the number served per unit time $(\mu)$, the number of visitor arrivals, and the number of visitors served. Then calculate the arrival and service intervals by experimenting with the intervals (for example: 5 minutes, 15 minutes, 30 minutes, 1 hour, etc.), so that we can get a time interval that is less the number of zeros. In this study a 30 minute time interval was used.

2. The data obtained must meet Steady, where $\lambda$ is the number of arrivals per unit time and $\mu$ is the number served per unit time. If it does not meet Steady State then the number of services must be increased or speed up the service time in accordance with the existing circumstances. This can provide improvements to existing service systems. Carry out a distribution match test for arrivals and visitors served by using the Kolmogorov Smirnov test and the Kai-Square test. If the hypothesis for the arrival 
distribution is accepted, then the distribution follows the Poisson distribution and if the hypothesis is rejected, the arrival distribution is generally distributed. Whereas if the hypothesis for the distribution of services is accepted, then the distribution follows the Exponential distribution and if the hypothesis is rejected, then the distribution of services is publicly distributed.

3. Determine the appropriate queue model. In this case, for each place, namely the counter legalized, counter changes in data, counters of birth, counters of death, divorce / marriage counters, counters counters.

\section{Results And Discussions}

\subsection{Steady State Size Analysis of Service System Performance}

Based on Table 1, there is a change in the number of servers for the birth counter, which in the first period amounted to 3 in the second period to 2 servers. In the table shows that, the value of $\varrho$ is less than 1 , this shows that the process of antrain in each window shows a steady state. In the first period, the number that was served at most per 30 minutes was the data change counter, while the number that was served the least was the legalized counter. Whereas for the second period, the average amount served at most per 30 minutes is the legalization part, but the average that is served at least is the birth counter. An increase in the average number of arrivals per 30 minutes from the first period to the second period.

Table 1. Steady State sie for services systems performance

\begin{tabular}{|c|c|c|c|c|c|c|c|c|}
\hline \multirow{2}{*}{ Loket } & \multicolumn{4}{|c|}{ First Period } & \multicolumn{4}{c|}{ Second Period } \\
\cline { 2 - 9 } & $\boldsymbol{c}$ & $\boldsymbol{\lambda}$ & $\boldsymbol{\mu}$ & $\boldsymbol{\rho}$ & $\boldsymbol{c}$ & $\boldsymbol{\lambda}$ & $\boldsymbol{\mu}$ & $\boldsymbol{\rho}$ \\
\hline $\begin{array}{c}\text { Counter 4 } \\
\text { (Legalized counter) }\end{array}$ & 2 & 6,2607 & 3,6358 & 0,8609 & 2 & 6,2329 & 10,1924 & 0,3058 \\
\hline $\begin{array}{c}\text { Counter 5/6 } \\
\text { (Data Changed } \\
\text { Counter) }\end{array}$ & 1 & 1,1267 & 6 & 0,1877 & 1 & 5,4521 & 9,9730 & 0,5469 \\
\hline $\begin{array}{c}\text { Counter 7, 8, dan 9 } \\
\text { (Birth Counter) }\end{array}$ & 3 & 4,755 & 4,84 & 0,327 & 2 & 6,2740 & 7,3557 & 0,4265 \\
\hline $\begin{array}{c}\text { Counter 10 } \\
\text { (Mortality Counter) }\end{array}$ & 1 & 1,5679 & 5,665 & 0,2768 & 2 & 5,5068 & 7,4603 & 0,3691 \\
\hline
\end{tabular}

With c: many servers / number of service facilities; $\lambda=$ average number of arrivals per 30 minutes; $\mu=$ average number served per 30 minutes; and $\varrho=$ level of service facility usage with $\varrho=\lambda /(\mathrm{c} \times \mu)$.

\subsection{Fit Test Distribution of Number of Arrivals and Service Time}

Distribution fit testing uses the Kolmogorov Smirnov and Chi Square test. In this study the number of arrivals was tested using Kolmogorov Smirnov. While testing the arrival time using Kolmogorov Smirnov and Chi Square. 
Table 2. Fit test distribution of the number of arrivals

\begin{tabular}{|c|c|c|c|c|c|c|c|c|}
\hline \multirow{2}{*}{ Counter } & \multicolumn{4}{|c|}{ First Period } & \multicolumn{4}{c|}{ Second Period } \\
\cline { 2 - 9 } & D & D table & Sig. & Decision & D & D table & Sig. & Decision \\
\hline $\begin{array}{c}\text { Counter 4 } \\
\text { (Legalized } \\
\text { counter) }\end{array}$ & 0,125 & 0,12021 & 0,036 & $\mathrm{H}_{0}$ rejected & 0,194 & 0,1592 & 0,008 & $\mathrm{H}_{0}$ rejected \\
\hline $\begin{array}{c}\text { Counter 5/6 } \\
\text { (Data Changed } \\
\text { Counter) }\end{array}$ & 0,100 & 0,12021 & 0,155 & $\mathrm{H}_{0}$ accepted & 0,254 & 0,1592 & 0,0001 & $\mathrm{H}_{0}$ rejected \\
\hline $\begin{array}{c}\text { Counter 7, 8, } \\
\text { dan 9 (Birth } \\
\text { Counter) }\end{array}$ & 0,185 & 0,12021 & 0,000 & $\mathrm{H}_{0}$ rejected & 0,256 & 0,1592 & 0,0001 & $\mathrm{H}_{0}$ rejected \\
\hline $\begin{array}{c}\text { Counter 10 } \\
\text { (Mortality } \\
\text { Counter) }\end{array}$ & 0,116 & 0,12021 & 0,066 & $\mathrm{H}_{0}$ accepted & 0,227 & 0,1592 & 0,0012 & $\mathrm{H}_{0}$ rejected \\
\hline
\end{tabular}

Table 2 shows the distribution fit test for the number of arrivals at each counter. There was a change in the distribution of arrivals at counters $5 / 6$ and counters 10 . These counters have Poisson distribution in the first period, but as the number of arrivals increased every 30 minutes from the first period to the second period, there was a change to the not Poisson distribution.

Table 3. Fit Test of Service Time Distribution

\begin{tabular}{|c|c|c|c|c|c|c|c|}
\hline \multirow{2}{*}{ Counter } & \multicolumn{3}{|c|}{ First Period } & \multicolumn{4}{c|}{ Second Period } \\
\cline { 2 - 7 } & $\chi^{\mathbf{2}}$ & $\chi^{\mathbf{2}} \boldsymbol{\alpha , v}$ & Decision & D & D table & Sig. & Decision \\
\hline $\begin{array}{c}\text { Counter 4 } \\
\text { (Legalized } \\
\text { counter) }\end{array}$ & 94,61 & 16,919 & $\mathrm{H}_{0}$ rejected & 0,191 & 0,064 & $6,77 \times 10^{-15}$ & $\mathrm{H}_{0}$ rejected \\
\hline $\begin{array}{c}\text { Counter 5/6 } \\
\text { (Data Changed } \\
\text { Counter) }\end{array}$ & 40,90 & 14,067 & $\mathrm{H}_{0}$ rejected & 0,169 & 0,068 & $2,60 \times 10^{-10}$ & $\mathrm{H}_{0}$ rejected \\
\hline $\begin{array}{c}\text { Counter 7, 8, } \\
\text { dan 9 (Birth } \\
\text { Counter) }\end{array}$ & 98,46 & 16,919 & $\mathrm{H}_{0}$ rejected & 0,202 & 0,063 & $<2,2 \times 10^{-16}$ & $\mathrm{H}_{0}$ rejected \\
\hline $\begin{array}{c}\text { Counter 10 } \\
\text { (Mortality } \\
\text { Counter) }\end{array}$ & 47,79 & 14,067 & $\mathrm{H}_{0}$ rejected & 0,163 & 0,068 & $1,05 \times 10^{-9}$ & $\mathrm{H}_{0}$ rejected \\
\hline
\end{tabular}

Table 3 shows the distribution match test for service time. Based on table 3, there is no change in distribution for service time. The results obtained indicate that the service time is not distributed by Poisson.

\subsection{Queue Model Systems}

Based on the results of the analysis of the steady state size of the performance of the service system and the fit test of the distribution of the number of arrivals and service times of visitors at the Semarang City population and civil registry office, the queuing system model obtained is as follows: 
Table 4. The Queue Model for Visitors of the Population and Civil Registry Office in the Semarang city

\begin{tabular}{|c|c|c|}
\hline Counter & $\begin{array}{c}\text { Queue model for First } \\
\text { Period }\end{array}$ & $\begin{array}{c}\text { Queue model for } \\
\text { Second Period }\end{array}$ \\
\hline Counter 4 (Legalized counter) & $(\mathrm{G} / \mathrm{G} / 2):(\mathrm{GD} / \infty / \infty)$ & $(\mathrm{G} / \mathrm{G} / 2):(\mathrm{GD} / \infty / \infty)$ \\
\hline Counter 5/6 (Data Changed Counter) & $(\mathrm{M} / \mathrm{G} / 1):(\mathrm{GD} / \infty / \infty)$ & $(\mathrm{G} / \mathrm{G} / 1):(\mathrm{GD} / \infty / \infty)$ \\
\hline Counter 7, 8, dan 9 (Birth Counter) & $(\mathrm{G} / \mathrm{G} / 3):(\mathrm{GD} / \infty / \infty)$ & $(\mathrm{G} / \mathrm{G} / 2):(\mathrm{GD} / \infty / \infty)$ \\
\hline Counter 10 (Mortality Counter) & $(\mathrm{M} / \mathrm{G} / 1):(\mathrm{GD} / \infty / \infty)$ & $(\mathrm{G} / \mathrm{G} / 2):(\mathrm{GD} / \infty / \infty)$ \\
\hline
\end{tabular}

Based on Table 4, it can be seen that there is a change in the queuing model at Counter 5/6; Lokt 7.8, and 9 and Leket 10. For Counter 4, there was no change in the queue model. Counter 5/6 in the first period with the model (M/G/1):( GD / $/ \infty)$, meaning that the Model is a queuing system model with the distribution of Poisson visitor arrivals, General service time distribution and the number of service counters operating as much as 1 waiters with first come first served rules.

\subsection{System Performance Measures}

From the queuing model obtained, the size of the queuing system performance for the first and second periods. Table 5 and Table 6 show the system performance measures with the statement $\mathrm{c}$ is the number of servers / number of service facilities; $\lambda$ is the average number of arrivals per 30 minutes; $\mu$ is the average number served per 30 minutes; $L$ is the estimated number of visitors in the system; $\mathrm{L}_{4}$ is the estimated number of visitors in the queue; $\mathrm{W}_{\mathrm{s}}$ is the estimated waiting time in the system; $\mathrm{W}_{\mathrm{q}}$ is the estimated waiting time in the queue; $\mathrm{P}_{0}$ is the probability that service personnel are unemployed.

Table 5. Measurement of Service System Performance in the City Population and Civil Registry Office of Semarang City in First Period

\begin{tabular}{|c|c|c|c|c|c|c|c|c|}
\hline Counters & $\boldsymbol{c}$ & $\boldsymbol{\lambda}$ & $\boldsymbol{\mu}$ & $\boldsymbol{L}_{\boldsymbol{s}}$ & $\boldsymbol{L}_{\boldsymbol{q}}$ & $\boldsymbol{W}_{\boldsymbol{s}}$ & $\boldsymbol{W}_{\boldsymbol{q}}$ & $\boldsymbol{P}_{\mathbf{0}}$ \\
\hline $\begin{array}{c}\text { Counter 4 } \\
\text { (Legalized counter) }\end{array}$ & 2 & 6,26 & 3,63 & 10,09 & 8,36 & 1,61 & 1,33 & $7,47 \%$ \\
\hline $\begin{array}{c}\text { Counter 5/6 (Data } \\
\text { Changed Counter) }\end{array}$ & 1 & 1,12 & 6 & 0,22 & 0,04 & 0,20 & 0,03 & $81,22 \%$ \\
\hline $\begin{array}{c}\text { Counter 7, 8, dan 9 } \\
\text { (Birth Counter) }\end{array}$ & 3 & 4,75 & 4,84 & 1,03 & 0,04 & 0,21 & 0,01 & $37,03 \%$ \\
\hline $\begin{array}{c}\text { Counter 10 } \\
\text { (Mortality Counter) }\end{array}$ & 1 & 1,56 & 5,66 & 0,36 & 0,08 & 0,23 & 0,05 & $72,32 \%$ \\
\hline
\end{tabular}

Table 5 and Table 6 show the queuing system performance measures for the first and second periods. Based on the table, it can be seen that there is an increase in the average number of arrivals every 30 minutes at each counter, although at counter 4 it can be assumed to be the same. While the average amount served is also increasing from the first period to the second period, it shows that there is speed of service in the system. While the estimated number of visitors in the system in the second period is less than 1, it shows that visitors do not have to wait long to be served. It is also shows the waiting time in the system and the waiting time in the second period is close to zero. It is different from the first period, the number of visitors at Counter 4 tends to accumulate. 
There is a queuing system for the first period that the opportunities for unemployed service personnel are very varied, counter 4 has the smallest chance of being unemployed compared to other counters, while counter $5 / 6$ has a very high chance of unemployment. This is certainly different from the second period, where in the second period shows the opportunity to manage it almost evenly around 40-50\%. In this analysis shows that the population and civil registration department of the city of Semarang has improved the queue system better. Customers are well served without waiting for a long time.

Table 6. Measurement of Service System Performance in the City Population and Civil Registry Office of Semarang City in First Period

\begin{tabular}{|c|c|c|c|c|c|c|c|c|}
\hline Counters & $\boldsymbol{c}$ & $\boldsymbol{\lambda}$ & $\boldsymbol{\mu}$ & $\boldsymbol{L}_{\boldsymbol{s}}$ & $\boldsymbol{L}_{\boldsymbol{q}}$ & $\boldsymbol{W}_{\boldsymbol{s}}$ & $\boldsymbol{W}_{\boldsymbol{q}}$ & $\boldsymbol{P}_{\mathbf{0}}$ \\
\hline $\begin{array}{c}\text { Counter 4 } \\
\text { (Legalized counter) }\end{array}$ & 2 & 6,23 & 10,19 & 0,61 & 0,001 & 0,10 & 0,0001 & $53,17 \%$ \\
\hline $\begin{array}{c}\text { Counter 5/6 (Data } \\
\text { Changed Counter) }\end{array}$ & 1 & 5,45 & 9,97 & 0,56 & 0,014 & 0,10 & 0,0026 & $45,33 \%$ \\
\hline $\begin{array}{c}\text { Counter 7, 8, dan 9 } \\
\text { (Birth Counter) }\end{array}$ & 2 & 6,27 & 7,36 & 0,86 & 0,004 & 0,14 & 0,0007 & $40,21 \%$ \\
\hline $\begin{array}{c}\text { Counter 10 } \\
\text { (Mortality Counter) }\end{array}$ & 2 & 5,51 & 7,46 & 0,74 & 0,003 & 0,13 & 0,0005 & $46,08 \%$ \\
\hline
\end{tabular}

\section{Conclusion}

Queue system at Counter 4 (counter legalized); counters 5/6 (counters of data changes), counters 7, 8, and 9 (counters of birth); counters 10 (counters of death) in the first and second periods are stable because they have a utility value of less than 1 . There is a change in the number of servers, namely at counters 7, 8, 9 (birth), which originally amounted to 3 reduced to two. The average number of arrivals in 30 minute intervals is more in the second period compared to the first period. In the first period the most number of arrivals was counter 4 , while in the second period the most number of arrivals was at counter 4 and counter 7, 8, 9. However, if you see the distribution of arrivals at each counter is almost the same, ranging from 5-6 visitors every 30 minutes. In the analysis of the two periods it was found that there has been an improvement in services at the Semarang City Occupation and Civil Registry Office. Service time is more efficient, fewer visitors waiting in the queue, so there are fewer visitors waiting in the system.

\section{Acknowledgment}

Thanks to Diponegoro Univesity for supporting as afounder in this research with number of contract 329-59/UN7.P4.3/PP/2019.

\section{Refferences}

[1] R. Bronson, Teori dan Soal-Soal Operation Research, Jakarta: Erlangga (1991)

[2] C. Knessl, D.I. Choi, and C. Tier, Society for Industrial and Applied Mathematics Journal 63, 398-422 (2002).

[3] T.J. Kakiay, Dasar Teori Antrian Untuk Kehidupan Nyata Yogyakarta Penerbit Andi (2004).

[4] Ross, S. M, Stochastic Processes. New York: John Wiley \& Sons, Inc (1983).

[5] C. Knessl, and H. Yao, Applied Mathematics Research express, 1,1-47 (2015). 
[6] D. Gross and C.M. Harris, Fundamental of Queueing Theory Thrid Edition, New York: John Wiley and Sons, Inc (1998).

[7] W.W. Daniel, Statistik Non Parametrik Terapan. Jakarta: PT. Gramedia (1989).

[8] T.C. Lee and K.I. Wong, Physica A, 461, 199-216, (2016).

[9] W. Li, D.D. Kouvatsos, and R.J. Fretwell, Computers and Operations Research, 78, 316-334 (2017).

[10] J. Luo, and V.G. Kulkarni, Queueing system, 79, 53-85 (2015). 